\title{
Entre a verdade e a heresia: representações iconográficas de Jacó Armínio como um herói reformador e perturbador da religião
}

\author{
Between truth and heresy: iconographic \\ representations of Jacobus Arminius as a hero \\ reformer and disturber of religion
}

\section{Entre la verdad y la herejía: representaciones iconográficas de Jacobus Arminius como um herói reformador y perturbador de la religión}

\author{
Vinicius Couto*
}

\begin{abstract}
RESUMO
Este artigo analisa duas das principais figuras da cultura visual inglesa dos séculos XVII e XVIII em que o teólogo holandês Jacó Armínio foi retratado de maneira antitética. Numa delas, ele foi apresentado juntamente com os reformadores protestantes primitivos e alguns ícones católicos de importante contribuição para o humanismo cristão; noutra figura, ele foi descrito visualmente como um perturbador da religião e um inimigo da Igreja da Inglaterra. Ambas as figuras foram baseadas em outras mais antigas que visavam demonstrar de modo hagiológico os principais contribuintes da reforma protestante. Enquanto a mais recente considera Armínio uma personagem importante, as mais antigas simplesmente o ignoram. Para analisar todas essas figuras, o presente ensaio toma como base as metodologias de Wölfflin e Panofsky, a fim de averiguar e apresentar o pano de fundo histórico, cultural e religioso que empreendeu uma batalha pela (in)tolerância religiosa no contexto europeu, sobretudo na Inglaterra.

Palavras-chave: Jacó Armínio; verdade; heresia; cultura visual; intolerância religiosa.
\end{abstract}

\begin{abstract}
This article analyzes two of the main figures of English visual culture from the 17th and 18th centuries in which the Dutch theologian Jacobus Arminius was portrayed in an antithetical way. In one, he was introduced along with early Protestant reformers and some Catholic icons of important contribution to Christian humanism; in another figure, he was described visually as a disturber of religion and an enemy of the Church of England. Both figures were based on older ones that aimed to demonstrate the main contributors to Protestant reform in a hagiological way. While the most recent one considers Arminius an important character, the older ones simply ignore him. In order to analyze all these figures, this essay is based on the methodologies of Wölfflin and Panofsky, in order to investigate and present the historical, cultural and religious background that waged a battle for religious (in)tolerance in the European context, especially in England.

Keywords: Jacobus Arminius; truth; heresy; visual culture; religious intolerance.
\end{abstract}




\begin{abstract}
RESUMEN
Este artículo analiza dos de las principales figuras de la cultura visual inglesa en los siglos XVII y XVIII en los que el teólogo holandés Jacobus Arminius fue retratado de forma antitética. En uno, fue presentado junto con los primeros reformadores protestantes y algunos íconos católicos de importante contribución al humanismo cristiano; En otra figura, fue descrito visualmente como un perturbador de la religión y un enemigo de la Iglesia de la Inglaterra. Ambas cifras se basaron en las anteriores que tenían como objetivo demostrar los principales contribuyentes a la reforma protestante de una manera hagiológica. Mientras que el más reciente considera que Arminio es un personaje importante, los más viejos simplemente lo ignoran. Para analizar todas estas cifras, este ensayo se basa en las metodologías de Wölfflin y Panofsky, con el fin de investigar y presentar los antecedentes históricos, culturales y religiosos que libraron una batalla por la (in)tolerancia religiosa en el contexto europeo, especialmente en Inglaterra.

Palavras clave: Jacobus Arminius; verdad; herejía; cultura visual; intolerancia religiosa.
\end{abstract}

\title{
Introdução
}

Os Países Baixos nos séculos XVI e XVII, em sua era dourada, experimentaram tempos de progresso cultural e tecnológico que marcaram o mundo. Apesar de todos esses avanços, a religiosidade não seguiu o mesmo caminho e em muitos momentos passou por retrocessos. Um evento emblemático sobre essa situação ocorreu entre 1618 e 1619, quando o Sínodo nacional de Dort tomou decisões unilaterais a respeito de qual deveria ser o posicionamento da Igreja Reformada da Holanda. Esse debate se deveu às ideias de um teólogo chamado Jacó Armínio (1560-1609), que trouxe apontamentos discordantes a respeito da forma como Deus governa o mundo e como opera a salvação. Os amigos e alunos que se simpatizavam com as ideias de Armínio, que ficaram conhecidos como remonstrantes, escreveram artigos protestando o calvinismo rígido. Nesse período, a produção panfletária aumentou de maneira considerável, passando de 70 unidades em 1615 para mais de 300 a partir de 1618 (HARMS, 2013, p. 278). Muitas dessas artes eram satíricas e sarcásticas, trazendo a narrativa de que o arminianismo é um mostro de cinco cabeças, uma teologia de confusão e divisão, um conjunto de ideias que atuariam como desserviço à reforma protestante e até mesmo uma carroça de esterco letal. ${ }^{1}$

Apesar da vasta quantidade de gravuras, pinturas e emblemas produzidos nos Países Baixos durante o entorno cronológico do Sínodo de Dort, este ensaio está focado principalmente em duas gravuras que foram produzidas fora do mundo holandês. Com a expulsão dos arminianos / remonstrantes, muitos precisaram sair em exílio e encontraram amparo na Inglaterra. Além

\footnotetext{
Essas retratações pejorativas são claramente vistas no emblema Arminiaensche dreckwaghen (A carroça de esterco arminiano) e na gravura Warminiaen, que era um retrato sinistro de um monstro humanoide arminiano de cinco cabeças.
} 
disso, paralelamente aos dias de Armínio, suas ideias já permeavam o ambiente inglês. Mesmo havendo na Igreja Anglicana uma forma de governo diferente da Igreja Reformada da Holanda, isso não impediu que Armínio e suas ideias sofressem as mesmas perseguições religiosas. O curioso, no entanto, é que Armínio fora retratado de maneira dupla: tanto como um herege que faria a Igreja da Inglaterra retornar ao romanismo, quanto como um importante pensador e teólogo que era digno de ser colocado entre os reformadores das primeiras gerações. A análise dessas figuras não é tão simples como parece. Por isso, recorro aqui às contribuições de Wölfflin e Panofsky, teóricos da área de cultura visual.

\section{Armínio entre os reformadores primitivos}

A primeira figura a ser analisada é a que foi batizada como The primitive reformers, datada de 1769. Começando por Wölfflin, destaco sua assinalação de que as principais características desse tipo de arte são a linearidade, os efeitos planares, a forma fechada, a pluralidade e a clareza. É possível perceber a linearidade nesta figura a partir do fato de que cada personagem está bem delineado e que a iluminação de todas as gravuras sempre oscila de um tom acinzentado para contrastes pretos e brancos (WÖLFFLIN, 2000, p. 2527). Quanto aos efeitos planares, é possível perceber, num primeiro plano, a centralidade de uma vela acesa sobre uma mesa; um segundo plano formado pelo grupo de pessoas ao redor superior da mesa, cujas personalidades destacam os reformadores, os quais compõem uma equipe de heróis; e um terceiro plano demonstrado por três pessoas, que juntamente com um animal, um cão, tentam apagar, de fora da mesa, a tal vela. A figura é simples, sem extrapolações caracteristicamente barrocas, o que denota uma forma fechada (WÖLFFLIN, 2000, p. 168), o que pode ser constatado na maneira como as personalidades estão todas equilibradas e enfileiradas. Há uma visível linearidade vertical e horizontal entre cada uma delas; as personalidades más, sempre na parte inferior das gravuras também estão sempre lineares de maneira horizontal e nunca na mesma nivelação dos reformadores. A ideia da pluralidade tem a ver com o princípio dos efeitos planares. Nos diversos planos da pintura renascentista, é possível perceber aspectos seccionados, como se cada seção tivesse locais, grupos, cores e ideias distintas. A clareza é a última característica levantada por Wölfflin. No caso das artes renascentistas, a objetividade é o mais importante, pois "a arte clássica coloca todos os meios de representação a serviço da nitidez formal" (WÖLFFLIN, 2000, p. 270). O barroco, em contrapartida, "evita sistematicamente suscitar a impressão de que o quadro 
tenha sido composto para ser visto e de que possa ser totalmente apreendido pela visão" (WÖLFFLIN, 2000, p. 270). Wölfflin chamou esse contraste de clareza absoluta (renascentismo) e clareza relativa (barroco). De fato, não parece ser o objetivo dos artistas suscitar nenhum tipo de emoção ou experiência sensória com a respectiva gravura. A clareza dela reside no simples fato de transmitir uma mensagem de que a centralidade das disputas religiosas da época estava no evangelho reacendido pelo cristianismo protestante em detrimento da malvadeza dos líderes católicos que estavam guiados por forças das trevas.

\section{Figura 01: Os Reformadores Primitivos - 1769 (anônimo)}

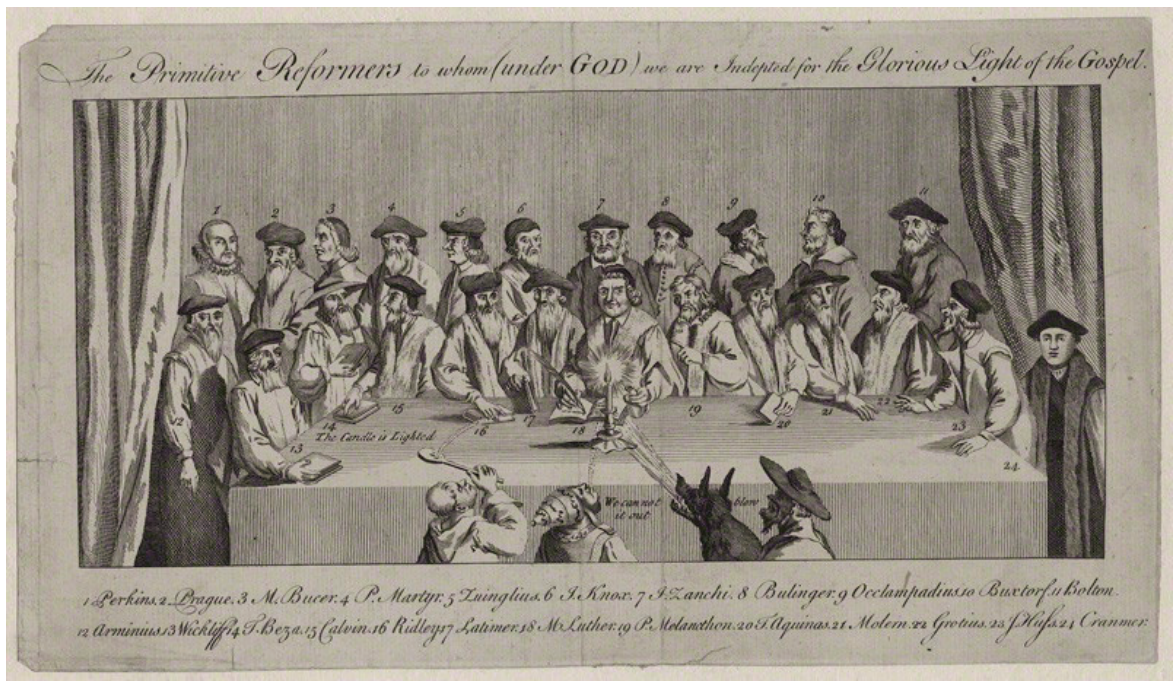

Fonte: National Portrait Gallery, Londres

Neste quadro, o autor retratou alguns dos principais nomes que estiveram envolvidos com a Reforma Protestante em suas diversas fases. Ele enumera 24 personalidades, as quais estão, respectivamente, ao redor e acima de uma grande mesa: (1) William Perkins (1558-1602), (2) Jerônimo de Praga (13701416), (3) Martin Bucer (1491-1551), (4) Peter Martyr Vermigli (1499-1562), (5) Ulrico Zuínglio (1487-1531), (6) John Knox (1514-1572), (7) Jerônimo Zanchius (1516-1590), (8) Heinrich Bullinger (1504-1575), (9) Johannes Oecolampadius (1482-1531), (10) Johannes Buxtorf (1564-1629), (11) Robert Bolton (1572-1631), (12) Jacó Armínio (1560-1609), (13) John Wycliffe (1324-1384), (14) Teodoro de Beza (1519-1605), (15) João Calvino (1509-1564), (16) Nicholas Ridley (1500-1555), (17) Hugh Latimer (1485-1555), (18) Martinho Lutero (1483-1546), (19) Philipp Melanchthon (1497-1560), (20) Tomás de Aquino (1225-1274), (21) Peter Du Moulin (1601-1684), (22) Hugo Grócio (1583-1645), (23) John Huss (1373-1415) e (24) Thomas 
Cranmer (1489-1556). ${ }^{2}$ Todos os ícones ali representados estão vestidos a caráter clerical, típico de cada uma de suas tradições religiosas e até mesmo cargos eclesiásticos, que misturam católicos, luteranos e reformados. Nas laterais da figura existem cortinas, dando um acabamento visual para a gravura.

Enquanto esses homens se destacam, a mesa também deve ser vista como um elemento central na figura, servindo como um aparato de divisão ambiental e possuidora de elementos de importante simbolismo. Nas laterais, bem como no ambiente superior da mesa, estão os chamados "reformadores primitivos", que, segundo o título da gravura, são To whom (under God) we are indepted for the glorious light of the Gospel, "A quem (sob Deus) devemos a gloriosa luz do Evangelho". A maioria dos homens não empunha nada nas mãos, senão especificamente Lutero (que escreve num papel com uma caneta típica da época), Latimer (que segura um livro), Ridley, Calvino e Wycliffe (que apoiam cada um deles um livro sobre a mesa), Beza (que segura um livro próximo ao peito) e Aquino (que apoia um livro diagonalmente sobre a mesa). As pessoas não estão dispostas em uma lógica cronológica. Mas não quer dizer que não haja uma lógica. É possível verificar alguns personagens que possuem alguma ligação histórica, de ideias e /ou denominacional, conforme a figura 02 a seguir, onde elenco onze grupos.

\section{Figura 02: Os grupos identificáveis na gravura "Os Reformadores Primitivos"}

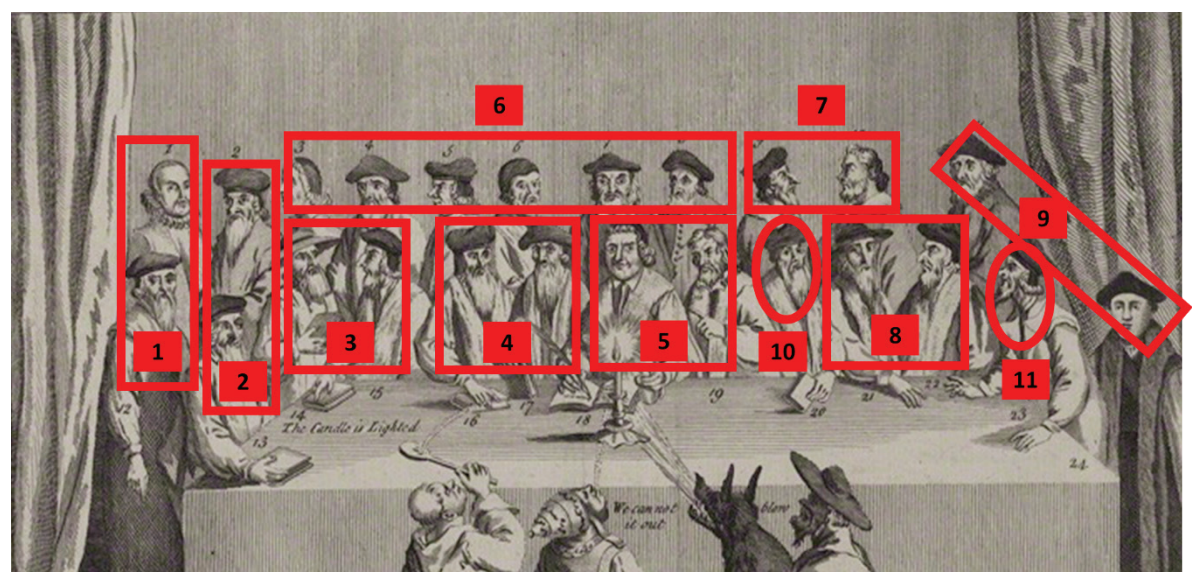

O primeiro grupo é destacável por Perkins e Armínio. Ambos debateram sobre soteriologia e eram membros da Igreja Reformada da Holanda.

2 Os nomes podem ser visualizados com mais nitidez na lista de STOWER, C. The Monthly Repository of Theology and General Literature. Vol. 7. Hackney: Longman, Hurst, Rees and Orme, 1813, p. 240. 
O segundo grupo tem Jerônimo de Praga e Wycliffe. Este foi um dos principais influenciadores (ao lado de Huss) daquele e ambos estão entre os primeiros reformadores. O terceiro grupo conta com Beza e Calvino. Ambos foram professores na Universidade de Genebra e este foi sucedido por aquele nesta função. O quarto grupo é formado por Ridley e Latimer, reformadores ingleses que foram condenados à fogueira e morreram juntos em 1555 ficando conhecidos como mártires de Oxford. O quinto grupo é representado por Lutero e Melanchthon, que além de estarem lado-a-lado, estão ao centro da mesa. Melanchthon foi nesse processo reformatório um importante redator e escritor das confissões da igreja luterana. O sexto grupo é interessante. Ele conta com diversos nomes da teologia reformada, cujo líder principal foi Zuínglio, mas que foi sucedido por Bullinger e que contou com grande apoio de Bucer. Esse trio fez inúmeros diálogos, bem como debates calorosos, com os luteranos a fim de pensar sobre uma confissão de Fé. Um importante documento dessa discussão foi a Confissão Helvética. Além deles, aparecem Vermigli, Knox e Zanchius, outro trio que foi importante para a difusão da teologia reformada e que sofreu influência direta de Zuínglio e principalmente de Calvino. Vermigli também foi altamente influenciado por Zuínglio e Bucer e se tornou um importante professor na Suíça, onde veio a óbito. Do último trio, Knox estudou com Calvino e ainda levou a teologia genebrina para a Escócia, seu país de origem. O sétimo grupo aponta os alemães Oecolampadius e Buxtorf se olhando de frente, dois humanistas cristãos que se envolveram com os estudos de hebraico. O oitavo grupo também conta com outra dupla que quase se olham de frente: Moulin é encarado por Grócio. O último foi um humanista holandês que defendeu o ponto de vista remonstrante ao período do Sínodo de Dort e o primeiro foi um francês que estudou em Leiden e que se tornou opositor do arminianismo, chegando até mesmo a escrever o livro Anatome Arminianismi (Anatomia do arminianismo). O nono grupo é formado pelos anglicanos Bolton e Cranmer, distintos líderes da reforma inglesa. Finalmente, os grupos décimo e décimo primeiro são os que parecem estar isolados, marcados pelo doutor angélico Tomás de Aquino e por John Huss.

Mas os detalhes da mesa ainda não acabaram. Bem ao centro dela está uma vela acesa, que faz jus ao título da gravura, "a luz do Evangelho". De acordo com essa titulação, os reformadores foram responsáveis por não deixar esse fogo se apagar. Por isso, a presença de John Wycliffe, John Huss e Jerônimo de Praga, os quais lutaram ao custo da própria vida pela manutenção desse luzeiro. Tomás de Aquino é uma figura interessante 
nessa figura. Ele provavelmente está ligado com essa fase inicial como um humanista cristão que deu peso à teologia, por meio de suas contribuições robustas. A mesa ainda possui uma pequena legenda destacando que "the candle is lighted” (a vela está acesa). Esse item nos leva à próxima visualização. Como já destacado, a mesa divide a figura em dois ambientes. Já vimos o superior. O ambiente inferior é composto por quatro outras personagens, que da esquerda para a direita, representam um monge católico, o Papa, um cão e um cardeal, também católico. Diferentemente dos líderes da Reforma, não há legenda para eles. É possível saber que se trata dessas pessoas por conta da vestimenta. Ademais, eles estão tentando apagar a vela, mas sem sucesso, e uma legenda indica isso, pois destaca que "we can not blow it out" (nós não podemos apagá-la). O Papa e o cão sopram contra a vela, o monge tenta atingi-la com algo que está empunhando e o cardeal parece apenas olhar o acontecimento e/ou ajudar o cão.

Outra curiosidade é o retrato de Armínio na figura 01. Os retratos mais conhecidos desse teólogo holandês (semelhantes à figura 03) não se parecem nem um pouco com a maneira como ele é representado ali. $\mathrm{Na}$ verdade, Perkins está mais parecido com ele. No entanto, existem alguns retratos curiosos de Armínio, em que ele aparece com um rosto mais jovem (figura 04), ora com uma fisionomia mais velha (figura 05), ora mais magro (figura 06) e ora com uma fisionomia mais gorda (figuras 07 e 08). ${ }^{3}$ A maneira como Armínio aparece na figura 01 é instigante, pois ele morreu jovem, com idade entre quarenta e nove e cinquenta anos e a forma como ele é retratado na figura 01 lhe deixou com uma aparência bem mais anciã. Sua barba também nunca é retratada tão grande como nessa primeira figura e seu corpo geralmente não é demonstrado como tendo um porte tão magro. As impressões que temos a partir dos vários retratos de Armínio são de que ele variava a gordura corporal do rosto, mas que era mais gordo em relação ao corpo, mesmo em figuras em que seu rosto está mais fino. Também não vemos nos seus retratos Armínio usando chapéu, como ocorre na figura $01 .^{4}$

\footnotetext{
3 Para acessar vários outros retratos de Armínio, confira TOLSMA, Marijke. Iconographia Arminiana: portraits from 1609 until ca. 1850. In: LEEUWEN, Marius van; STANGLIN, Keith; TOLSMA, Marijke. Arminius, arminianism and Europe: Jacobus Arminius (1559/60-1609). Boston; Leiden: Brill, 2009, p. 239-61.

4 Para ver outras pinturas de Armínio com o corpo completo, ver a mesma obra TOLSMA, Marijke. Facing Arminius: Jacobus Arminius in Portrait. In: LEEUWEN, Marius van; STANGLIN, Keith; TOLSMA, Marijke. Arminius, arminianism and Europe: Jacobus Arminius (1559/60-1609). Boston; Leiden: Brill, 2009, p. 203-38.
} 
Figura 03: Porträt Jacobus Arminius

- 1662 (Matthaeus Merian)

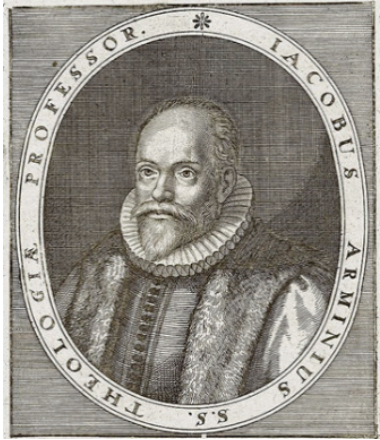

Fonte: Bibliothek

Universität Augsburg, Augsburg

Figura 05: Porträt Jacobus Arminius - 1788 (Reinier Vinkeles)

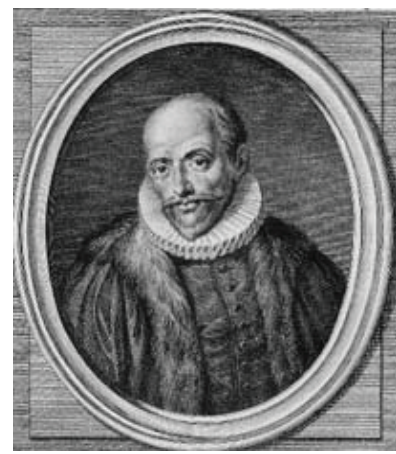

Fonte: VU University

Amsterdam Library, Amsterdam

Figura 07: Portrait of Jacobus Arminius - s.d. (Anônimo)

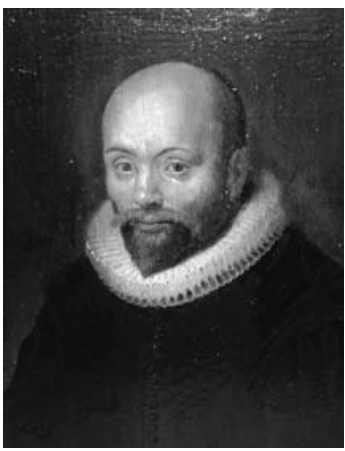

Fonte: Remonstrantse Gemeente, The Hague
Figura 04: Porträt JacobusArminius - s.d (Matthaeus Merian)

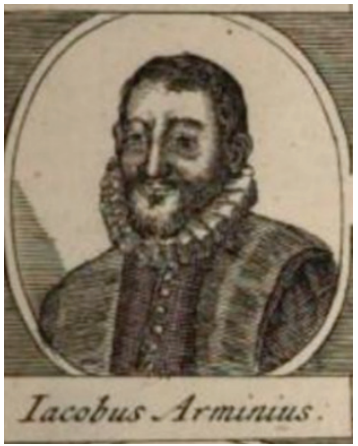

Fonte: GOTTFRIED, 1698, p. 2 IX. TAFEL

Figura 06: Portrait of Arminius c. 1705 (Christoffel Lubienitzki)

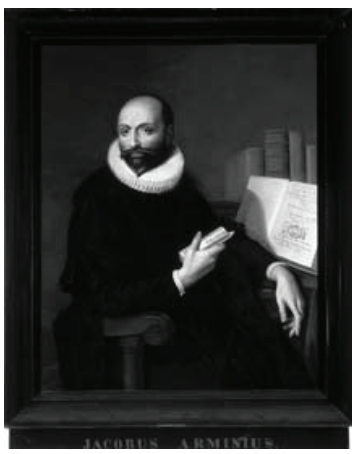

Fonte: Museum

Catharijneconvent, Utrecht

Figura 08: Porträt Jacobus Arminius - c. 1613 (Anônimo)

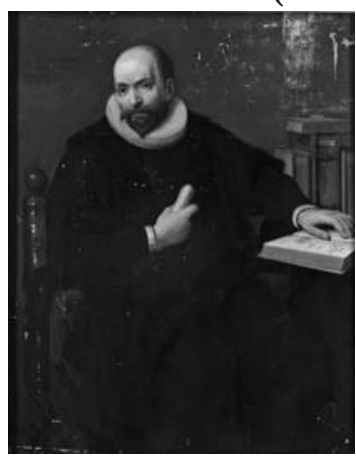

Fonte: Kunsthistorisches Museum, Vienna 
A figura 01 foi editada e pintada em óleo em algum momento do final do século XVIII. O modelo é o mesmo e mantém os mesmos personagens enfileirados horizontalmente em duas posições. No entanto, pequenas mudanças são importantes de serem ressaltadas. $\mathrm{O}$ autor inverteu a ordem dos personagens, trocando-os da direita para a esquerda. Enquanto na figura 01 a sequência é de 1 a 11 na fileira superior, na figura 09 temos de 11 a 1 (embora não apareça essa legenda). De qualquer modo, a sequência deles é exatamente a mesma, mas varia a quantidade de reformadores: na figura 01 temos vinte e quatro e na figura 09 temos um a menos, que apesar de não termos clareza com as legendas, em função do fundo bastante escuro por conta do tipo de pintura, sabe-se por um documento da Galleria Mizar de Roma que Thomas Cranmer é o personagem que foi excluído. Não é possível saber a razão dessa exclusão. Pode ser alguma observação enviesada do pintor editor. De qualquer modo - também por meio do documento do Museu -, Armínio é mantido nessa pintura (MIZAR, [s.d.], p. 1). Ele está na extrema esquerda de Lutero (o qual está centralizado à mesa e de frente para a vela acesa escrevendo num livro), no mesmo nivelamento horizontal do reformador alemão. Armínio também está abaixo de William Perkins, seguindo o mesmo padrão da figura 01, e está retratado com a mesma aparência: com barba longa e afinada, magro, mais velho, com um chapéu sobre a cabeça e com uma das mãos para baixo.

\section{Figura 09: Os Reformadores Primitivos em tela de óleo - c. século XVIII (anônimo)}

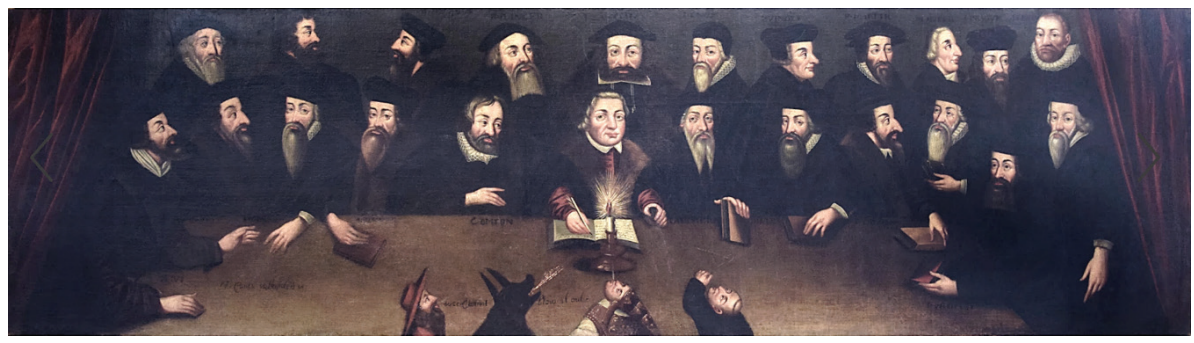

Fonte: Galleria Mizar, Roma

A fim de explicar melhor essa figura, ainda podemos pensar o método de Wölfflin em relação ao método de Panofsky. A metodologia panofskyana segue três passos. O primeiro deles, o pré-iconográfico, parte da ideia do que ele denominou de "mundo das formas puras", que de acordo com ele, é composto "de significados primários ou naturais [e] pode ser chamado de mundo dos motivos artísticos". Esse mundo pode ser "apreendido pela 
identificação das formas puras", ou seja, "certas configurações de linha e cor, ou determinados pedaços de bronze ou pedra de forma peculiar, como representativos de objetos naturais tais que seres humanos, animais, plantas, casas, ferramentas [...] pela identificação de suas relações mútuas como acontecimentos" e "pela percepção de algumas qualidades expressionais, como o caráter pesaroso de uma pose ou gesto, ou a atmosfera caseira e pacífica de um interior" (PANOFSKY, 1991, p. 50). O primeiro passo visa detectar o "tema primário ou natural" e o segundo o "tema secundário ou convencional". O segundo tema consiste "no mundo dos assuntos específicos ou conceitos manifestados em imagens, estórias e alegorias, em oposição ao campo dos temas primários ou naturais manifestados nos motivos artísticos" (PANOFSKY, 1991, p. 51). Finalmente, o último passo deseja obter o "significado intrínseco ou conteúdo", que de acordo com Panofsky, "é apreendido pela determinação daqueles princípios subjacentes que revelam a atitude básica de uma nação, de um período, classe social, crença religiosa ou filosófica - qualificados por uma personalidade e condensados numa obra” (PANOFSKY, 1991, p. 52). Deste modo, em diálogo com Wölfflin e Panofsky, ainda podemos extrair mais informações, partindo para a busca dessas representações iconográficas em outras produções semelhantes.

\section{Os reformadores primitivos em edições anteriores}

Em se tratando da figura 01, a gravura é de autoria desconhecida e foi publicada em 1769. Esta gravura é baseada em outra mais antiga, datada de 1640 (figura 10) e/ou noutra que pode ter sido elaborada entre 1640 e 1684 (figura 11). A figura 01 é mais provavelmente uma adaptação e ampliação da pintura intitulada "A Reforma" (figura 10), que de acordo com a National Portrait Gallery, foi publicada por volta de 1640. De autoria desconhecida, ela tem exatamente a mesma mensagem: alguns dos principais nomes da Reforma Protestante são representados unidos ao redor de uma mesa (Wycliffe, Melanchthon, Bradford, Bullinger, Cranmer, Zuínglio, Lutero, Latimer, Bucer, Calvino, Jerônimo de Praga, Perkins, Beza, Ridley e Tyndale). A primeira figura possui um total de vinte e quatro reformadores ao passo que a figura 10 possui apenas quinze. Com exceção de Bradford, todos da figura 10 estão contidos na figura 01. Semelhantemente à primeira figura, ela mantém os reformadores sempre na parte superior da mesa, de modo que eles se espalham pelas laterais, mas nunca se alinham, em linearidade, com os "inimigos da Igreja" que permanecem na parte inferior. A figura 10 também possui a mesma mensagem da vela, com a legenda "the candle is 
lighted' (a vela está acesa). Do mesmo modo que na figura anterior, Lutero é apresentado ao centro da mesa e de todos os ícones reformatórios, mas dessa vez escreve num livro com uma caneta mais simples e um olhar mais manso, acompanhado à sua destra de seu ajudante Melanchthon. A disposição dos personagens não parece seguir a mesma lógica da figura 01. Dessa vez, podemos perceber mais perto de Lutero os nomes que geralmente são considerados mais destacáveis na liderança da Reforma: do seu lado esquerdo está Calvino, acima está a dupla Zuínglio e Bucer, e à sua direita na parte superior o reformador inglês, Cranmer.

Figura 10: A Reforma - 1640 (anônimo)

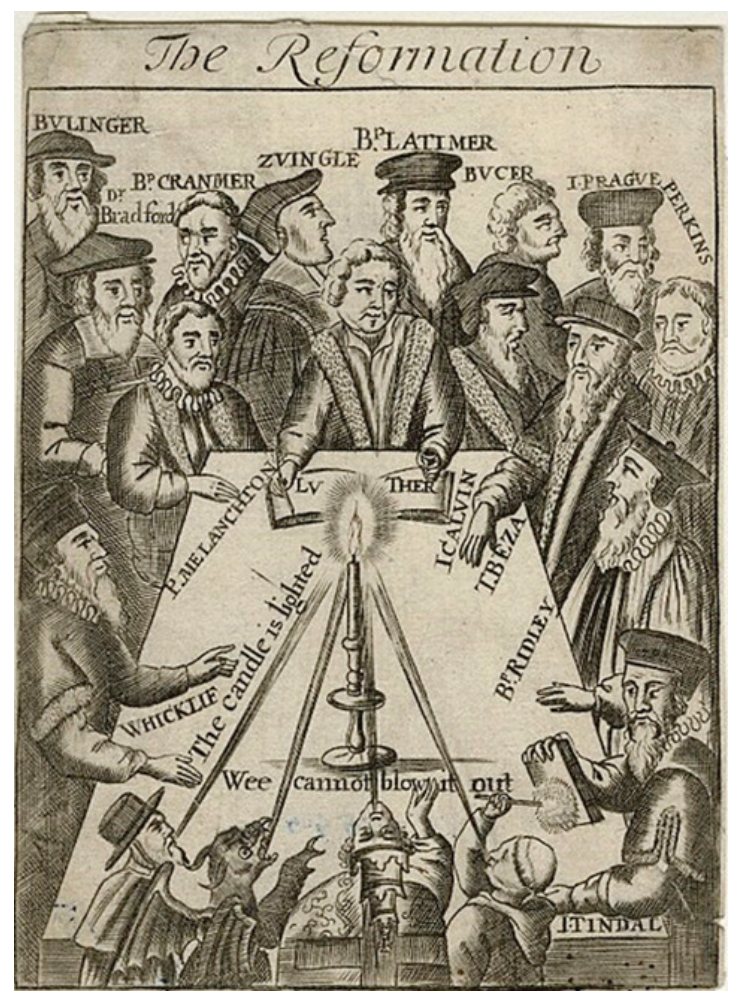

Fonte: National Portrait Gallery, Londres

A mesa novamente possui o mesmo sentido divisional, planificando o grupo superior do inferior. No entanto, antes de olharmos para essa divisão, é válido ressaltar que, ao centro da mesa, a luz do Evangelho novamente sofre ataques de católicos, que dessa vez estão em ordem diferente da figura 01, mas que representam exatamente a mesma ideia imagética. Da esquerda para direita, vemos um cardeal, o Papa e um monge, que podemos reconhecer 
pelas indumentárias. Além desses líderes católicos, há a presença de satanás, que está entre o cardeal e o Papa, representado desta vez por um dragão. $\mathrm{Na}$ figura 01, satanás estava representado por um cão. Temos, ainda, a mesma legenda aparece aqui: "wee can not blow it oul" ("não podemos apagá-la"). Ao que parece, a tentativa de todos os católicos e de satanás é de apagar a vela com o sopro de suas bocas, que está representado por algumas linhas que vão em direção à vela. Essa representação é repetida em diversas outras pinturas e gravuras que foram editadas com base na mais antiga, cuja autoria é de Thomas Jenner, um vendedor de livros britânico. ${ }^{5}$

Jones comentou que esta gravura foi provavelmente produzida no início do século XVII na Inglaterra e pretendia, além de exaltar o protestantismo, demonstrar uma visão religiosa anticatólica, algo bastante típico no início da Reforma Protestante. Além disso, ele ainda explicou que a frase "A vela está acesa. Não podemos apagá-la”, aponta para uma citação parafraseada do livro apócrifo de Esdras 14:25 feita por Hugh Latimer a Nicholas Ridley enquanto ambos eram queimados numa fogueira em 16 de Outubro de 1555: "Hoje vamos acender essa vela pela graça de Deus na Inglaterra, e eu confio que nunca será apagada" (JONES, 2003, p. 364). Eles ficaram conhecidos como os mártires de Oxford. Vale ainda ressaltar que, nesta imagem William Tyndale é o único a empunhar uma Bíblia. Ele a segura e aponta na direção dos líderes católicos e de satanás. Tyndale foi executado em 1536, tendo sido "estrangulado até a morte enquanto amarrado na fogueira, e então seu corpo foi queimado" (FARRIS, 2007, p. 37). Ele acabou sendo preso e condenado por crime de heresia por se opor a diversas crenças oriundas do catolicismo romano e, principalmente, por ter denunciado como antibíblico o divórcio do Rei Henrique VIII. Não foi à toa que suas últimas palavras foram: "Senhor! Abra os olhos do rei da Inglaterra" (DANIELL, 2001, p. 383). Uma vez que o autor desta gravura seja mais provavelmente britânico, conforme apontou Jones, as últimas palavras de Latimer e a postura de Tyndale parecem ser bastante relevantes nesta produção com o intuito de destaca-los dentre os demais reformadores.

\footnotetext{
Spaans começa sua análise das "faces da Reforma" a partir da gravura "The candle is lighted" (A vela está acesa). De acordo com ele, a data de publicação é incerta, mas deve estar entre 1630 e 1640. Essa figura também retrata quinze ícones, como a figura 10, mas ao invés de apresentar Cranmer, Latimer e Bradford, aponta para Huss, Knox e Zanchi. Ela também alterna o imagético de satanás, que está representado por um touro. Os demais elementos (mesa com vela, reformadores ao redor e acima da mesa, os inimigos da Igreja na parte inferior) estão todos explicitamente iguais. Para mais informações, ver SPAANS, Joke. Face of the Reformation. In: Church History and Religious Culture, Utrecht, v. 97, n. 1, 2017, p. 408-51.
} 
A figura 11 é interessante de ser comparada. Ela é homônima à 10 e foi produzida entre 1640 e 1684 e de autoria anônima. Ela seguia o mesmo padrão das duas anteriores, mas possui mais qualidade que as anteriores, trazendo detalhes dos rostos e das vestes dos líderes católicos de um modo bem mais peculiar. Em termos de semelhança, destacamos a centralidade da mesa, onde novamente encontramos a personagens icônicos da Reforma numa posição superior aos católicos. Essa figura alterna os nomes dos que estão ao redor da mesa (Wycliffe, Huss, Jerônimo de Praga, Zuínglio, Oecolampadius, Bucer, Calvino, Beza, Melanchthon, Vermigli, Knox, Matthias Flacius, Bullinger, Zanchius e Perkins) e ainda coloca, ao fundo, um quadro com outros expoentes que colaboraram nas reformas religiosas: Georgius Princeps Anhaldinus (1507-1553), Johannes Alasco (1499-1560), William Farel (1489-1565), Johannes Sleidanus (1506-1556), Philip Mauxius (1540-1598) e Franciscus Junius (1545-1602). A frase, ao centro, está em holandês e significa: "A luz do candelabro está acesa". Semelhantemente às outras duas figuras (mesmo as versões alemã e latina da mesma gravura), sempre na parte inferior, os católicos, representados pela figura do Papa, de um cardeal e de um monge, tentam, sem êxito, e influenciados por satanás (desta vez na figura de uma besta), apagar a chama do Evangelho.

Figura 11: Os Reformadores - c. 1640-1684 (anônimo)

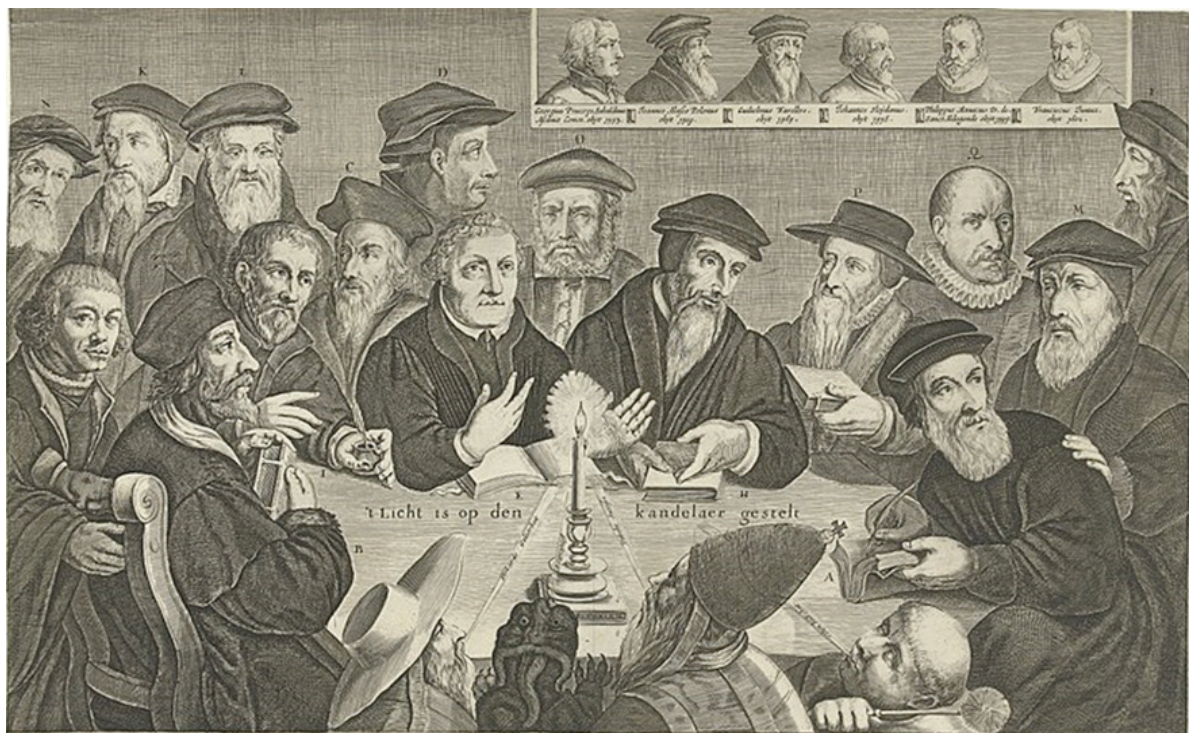

Fonte: National Portrait Gallery, Londres 
Chama a atenção o fato de que em todas as três figuras, encontramos os três líderes católicos acompanhados de um ser maligno, respectivamente um cão, um dragão e agora uma besta. Essa alusão tem a ver com o tipo de escatologia do período da Reforma, visto que os reformadores (Lutero, Calvino, Thomas Cranmer, John Knox e outros) assumiram uma posição escatológica historicista e identificavam os papas com os "muitos anticristos [que] têm surgido" (1 João 2:18). A Igreja Católica era a "grande prostituta que está sentada sobre muitas águas, com quem os reis da terra se prostituíram; os habitantes da terra se embriagaram com o vinho da sua prostituição" (Apocalipse 17:1,2). "Essa informação é importante, pois Armínio viveu neste ínterim de anticatolicismo e por muitas vezes foi acusado de papista. A seção seguinte se encarrega de demonstrar um pouco melhor acerca dessas acusações. A questão inquietante, é: por que Armínio não aparece nas figuras 10 e 11, mas aparece na composição de uma célebre assembleia de reformadores da figura 01? Seria Armínio um vilão da reforma religiosa ou poderia ele se unir ao conjunto de "heróis" listados nas gravuras?

Ao que parece, a questão de Armínio ser ou não um reformador na cultura visual protestante europeia, pode estar diretamente ligada aos pressupostos das pessoas que elaboraram as gravuras ou de quem as encomendou, afinal, existem alguns contemporâneos de Armínio nas figuras, como William Perkins, Theodoro de Beza e Francis Junius, todos com os quais Armínio chegou a ter contato. As figuras 10 e 11 possuem um teor mais anticatólico do que a primeira, que além de ter tido um quadro mais amplo de reformadores, ainda elencou Tomás de Aquino, um católico medieval que, apesar de ser reconhecido por diversas contribuições teológicas até mesmo por protestantes, não se enquadra nos contextos históricos da Reforma, visto que muito da teologia oficial católica é aquiniana. Tudo indica que o autor da figura 01 tenha sido alguém com maior espírito de catolicidade e tolerância (provavelmente um anglicano adepto da assim chamada via media), razão pela qual Armínio também está incluso na grande lista de reformadores. ${ }^{7}$ Se Armínio puder ser contabilizado entre os reformadores, então ele também pode ser visto como um "herói” religioso. Contudo, a imagem que seus opositores venderam, era a de que ele fora um herege, um papista e tipo de arruaceiro da ordem política e religiosa.

\footnotetext{
6 Para maiores informações, ver GUINNESS, H. Grattan. Interpretation and use of these prophecies in Reformation times. In: Romanism and the Reformation: From the Standpoint of Prophecy. Eugene: Wipf and Stock, 2007, p. 223-60.

Uma pesquisa interessante sobre essas figuras da Reforma, bem como às reações católicas e sobre o envolvimento anglo-neerlandês do debate entre calvinismo e arminismo, ver SPAANS, 2017, p. 446-47.
} 


\section{Jacó Armínio: um reformador protestante ou um romanista enrustido? Armínio entre a verdade e a heresia}

Armínio foi membro da Nederduitse Gereformeerde Kerk (Igreja Reformada da Holanda), tendo sido ordenado em 1588 e servido como pastor da comunidade de Amsterdã, a Oude Kerk (Igreja Antiga), entre 1587 e $1603^{8}$. Sua denominação, portanto, era de orientação protestante, numa época ainda recente em relação à Reforma religiosa, de maneira geral. A Igreja Reformada da Holanda foi fundada em 1571 com a realização do Sínodo de Emden. Nesta reunião participaram vinte e nove líderes que, além de organizarem a nova denominação religiosa, também estabeleceram que a Confissão Belga e o Catecismo de Heidelberg seriam os documentos confessionais oficiais. Eles também determinaram que a nova denominação seria dividida em quatro níveis administrativos: consistórios locais, presbitérios, sínodos regionais e sínodo nacional. Este Sínodo também definiu que a Igreja Reformada da Holanda seria, a partir de então, a denominação religiosa oficial e pública dos Países Baixos. Neste ínterim, propriedades católicas foram confiscadas e reutilizadas pela nova Igreja oficial (NIJENHUIS, 1994, v. 2, p. 101-24).

O clima relacional entre católicos e protestantes ainda era de acidez nos demais países que aderiram à reforma religiosa, de modo que os primeiros sempre acusavam os protestantes de dissidentes e até mesmo hereges, ao passo que estes tratavam a Igreja Católica como uma grande apóstata, uma instituição religiosa guiada por satanás. Embora o protestantismo, em suas primeiras denominações, tenha se esmerado para estabelecer seus credos, catecismos e confissões, o princípio do Sacerdócio Universal dos Crentes, a ojeriza para com o episcopado papal, a não aceitação da tradição como fonte primária de autoridade e a primazia das Escrituras como fonte autoritativa de fé e prática, fizeram com que não houvesse um padrão unificado de crença. No decorrer da própria Reforma ocorreram diversos entendimentos controversos. Um exemplo disso pode ser constatado na questão da Ceia do Senhor. Para Lutero, a visão adequada era a da consubstanciação; Zuínglio entendia que o correto era a do memorial; Calvino, por sua vez, adotou uma perspectiva dialética entre as posições luterana e zuingliana, chegando à proposição da presença real de Cristo nos sacramentos (GEORGE, 1993, p. 145-52).

\footnotetext{
8 Para maiores informações biográficas de Jacó Armínio, ver BANGS, Carl. Armínio: um estudo da Reforma Holandesa. São Paulo: Reflexão, 2015. Ver, ainda, GUTHRIE, John. The life of James Arminius. Nashville: E. Stevenson \& F.A. Owen, 1857; BANGS, Nathan. James Arminius: Formerly Professor of Divinity in the University of Leyden. New York: Harper and Brothers, 1843; BRIAN, Rustin E. Jacó Armínio: o homem de Oudewater. São Paulo: Reflexão, 2018.
} 
O que esquentou a Holanda nos séculos XVI e XVII foram os debates soteriológicos. Armínio discordou de muitos pontos da teologia reformada de João Calvino e de Teodoro de Beza, sucessor de Calvino na Universidade de Genebra. Beza, que fora professor de Armínio em Genebra, reformulou o calvinismo para uma visão mais rígida, supralapsariana e que se adequasse melhor à lógica argumentativa. Para Beza, os decretos de Deus foram todos realizados antes mesmo da Queda de Adão (supralapsarianismo). Uma vez que a temporalidade para Deus era algo completamente diferente do modo como as criaturas entendem, vivem e experienciam, a consequência lógica teria que ser mesmo essa, levando-se às últimas consequências. Assim, Beza definiu com mais rigor a ideia de que Deus só conhece o futuro porque Ele mesmo o colocou à maneira de decreto. Nesse sentido, Deus não apenas é o agente de todas essas coisas determinadas por Ele próprio, como também possui uma presciência passiva, subordinada aos decretos de seus desígnios?. Essa foi uma das razões pelas quais Armínio se posicionou contra o protótipo de hipercalvinismo bezano, pois de acordo com suas ponderações, Deus ser o agente de tudo o que acontece leva automaticamente o Criador para o banco dos réus, tornando-o, inequivocamente, o autor do próprio pecado. A responsabilidade pelo mal moral, outrossim, é cabível a Deus e não ao pecador, haja vista que este está tão somente obedecendo aos desígnios divinos preparados para ele desde a eternidade passada. Neste sentido, qual seria a lógica do impenitente ser condenado? Para Armínio, a predeterminação divina é incompatível com a Bíblia por quatro razões:

Primeiro, faz Deus ser o autor do pecado, e o homem ser isento de culpa. Em segundo lugar, constitui-se Deus como o único e justo pecador verdadeiro: Porque quando há uma lei fixa que proíbe esse ato, e quando há uma tal "predeterminação" que faz com que seja "impossível para este ato não ser comprometido", segue-se como consequência natural que é Deus mesmo que transgride a lei, uma vez que Ele é a pessoa que realiza essa ação contra a lei. Pois mesmo que seja imediatamente perpetrada pela criatura, ainda, em relação a isso, a criatura não pode ter qualquer consideração do pecado; porque esse ato era inevitável por parte do homem, após essa "predeterminação" ter sido afixada. Em terceiro lugar, porque, de acordo com este dogma, Deus precisava do pecador e do seu pecado para ilustrar a sua justiça e misericórdia. Em quarto lugar, a partir destes termos, o pecado não é mais pecado (ARMíNIO, 2015, v. 1, p. 273).

\footnotetext{
9 Além do predestinacionismo rígido, Beza também foi o responsável pela inserção da expiação limitada, por ter uma preocupação maior com a consistência lógica do que tinha Calvino. Cf. STEINMETZ, David C. Theodore Beza (1519-1605): eternal predestination and divine sovereignty. In: Reformers in the wings: from Geiler von Kaysersberg to Theodore Beza. New York: Oxford University Press, 2001, p. $118-20$.
} 
As elucubrações do teólogo de Oudewater geraram disputas teológicas acirradas. Alguns de seus alunos e amigos, influenciados por suas ideias, escreveram panfletos com cinco artigos no ano de 1610, com o intuito de protestar contra o ensino rígido bezano. Em função desta atitude, ficaram conhecidos como remonstrantes ${ }^{10}$. Armínio poderia ser visto como um herege, um vilão que ia contra as crenças formais de sua Igreja; ou poderia ser tido como um reformador, isto é, um tipo de herói que está preocupado em sempre confrontar o ensino de sua denominação com os textos sacros, seguindo o próprio princípio reformado do sola Scriptura. Em 1769, algum artista enxergou nele a segunda opção e o incluiu com diversos outros reformadores clássicos mais famosos. No entanto, esse tipo de reconhecimento não foi natural e Armínio foi demonizado em diversas narrativas textuais e visuais como sendo um vilão da pior espécie. Seus seguidores também eram encarados da mesma forma e mesmo os que apenas se simpatizavam com seu pensamento foram também retratados como esterco que seguia o mesmo caminho de despejo pós-dortiano ${ }^{11}$. Mesmo apesar de todo este repúdio ao arminianismo, esse pensamento traspassou fronteiras geográficas e foi comumente adotado por alguns Bispos na Igreja da Inglaterra. John Wesley (1703-1791) foi um desses clérigos anglicanos que aderiu ao arminianismo. Entretanto, muito antes dele, havia outros ministros que estavam imersos nesta perspectiva teológica. Cannon, um estudioso da teologia e biografia de John Wesley, apontou que os pais dele, Samuel e Suzana, eram já adeptos do que era conhecido como "arminianismo inglês" (CANNON, 1946, p. 45), que de acordo com o Global Dictionary of Theology, foi um movimento independente surgido durante o reinado de Elizabete I (1558-1603) e cujos adeptos repudiavam o calvinismo como um todo, principalmente os axiomas da graça irresistível e da predestinação (DYRNESS; KÄRKKÄINEN, 2008, p. 62)..$^{12}$ Mesmo assim, em 1641 foi feita uma petição anônima na Inglaterra para que o arminianismo fosse banido e considerado como herético. A petição também continha uma gravura pejorativa:

10 Remonstrância significa protesto. Os artigos remonstrantes defendiam a depravação total, a condicionalidade da eleição, a universalidade da expiação, a iniciativa da graça divina na ordo salutis, bem como sua resistibilidade. Sobre a possibilidade real de apostasia eles deixaram em aberto, vindo a se posicionarem mais claramente em 1618, na nova confissão de fé. Os primeiros cinco artigos de 1610 podem ser vistos em SCHAFF, Phillip. The Creeds of Christendom, v. 3. Grand Rapids: Baker Book House, 1990, p. 545-49. Para os novos artigos de 1618, ver COUTO, Vinicius. Anexo 02: As opiniões dos remonstrantes em 1618 com um memorial a Jacó Armínio. In: Em favor do arminianismo-wesleyano: um estudo bíblico, teológico e exegético de sua relevância na contemporaneidade. São Paulo: Reflexão, 2016, p. 373-88.

11 Para mais informações sobre esse caso, ver a figura Arminiaensche dreckwaghen.

12 Uma obra completa sobre o tema "arminianismo inglês" é TYACKE, Nicholas. Anti-Calvinists: the rise of English Arminianism c. 1590-1640. New York: Oxford University Press, 1987. 
Figura 12: Armínio entre a verdade e a heresia - 1641 (anônimo)

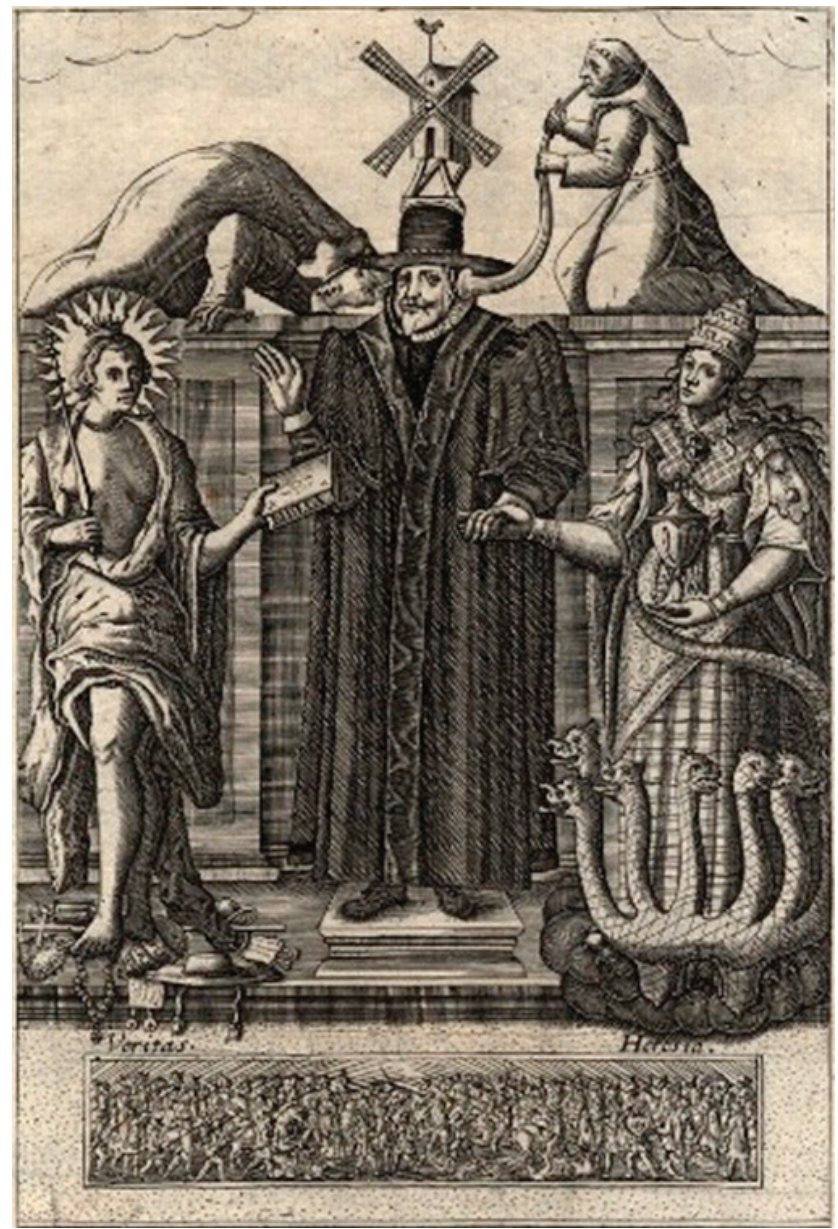

Fonte: National Portrait Gallery, Londres

Seguindo o padrão clássico renascentista, a gravura mostra sua linearidade e efeitos planares ao deixar bem delineados cada uma das personagens, a saber: Armínio, ao centro; a verdade à [nossa] esquerda; a heresia à direita; um monge no canto superior direito; um jesuíta no canto superior esquerdo; além de um moinho de vento vertical na parte superior central. Pensando em formato fechado, podemos dividir a figura em seis quadrantes, e perceber que cada um dos pontos enfatizados não fica de fora da gravura. Pensando no significado intrínseco de Panofsky, podemos explicar um pouco da razão desta petição. De acordo com o documento, a doutrina arminiana traria ódio e dissensão, além de destruição para a Igreja e para o Estado, por isso deveria ser repudiada e proibida. Isso também aponta para a clareza objetiva 
de Wölfflin. No catálogo de impressões e desenhos do Museu Britânico, essa gravura é apresentada como Arminio entre a verdade e a heresia. Há, ainda, algumas explicações sobre a figura que estão em conformidade tanto com a pluralidade de Wölfflin e quanto com os temas primário e secundário de Panofsky. Como se pode ver, a mão direita de Armínio está levantada em sinal de rejeição à verdade, que empunha uma Bíblia. A verdade ainda está pisando diversos símbolos do papado, como sinal de rejeição ao catolicismo. Contudo, a figura indica que Armínio, ao invés de seguir o caminho da verdade, está de mãos dadas com a heresia, uma figura apocalíptica representada por um "dragão [...] com sete cabeças" com coroas e carregando um cálice (Apocalipse 12:3). O moinho é um símbolo holandês, aludindo à nacionalidade de Armínio. ${ }^{13}$ Porém, o artista ainda quis retratar Armínio como um papista, de modo que de um lado, um monge sussurra em seus ouvidos, ao passo que do outro, um jesuíta fala com ele por meio de um trompete. ${ }^{14}$

Além disso, ainda podemos evocar as figuras 01, 09 e 10 em comparação com esta última gravura de Armínio. Lembremos que as três primeiras sempre traziam quatro personagens do mal, as quais tentavam incessantemente apagar a vela do evangelho: o Papa, um cardeal e um monge, além de Satanás representado ora por um cão, ora por um dragão e ora por uma besta. Essas quatro personagens estão aqui também. A figura que representa a heresia tem duplo simbolismo: é tanto o Papa, quanto Satanás, o dragão de sete cabeças, pois na escatologia historicista, o Papa é o anticristo; o monge está representado no canto superior direito; o jesuíta, no canto superior esquerdo, não está lá à toa. Esta ordem católica, mais precisamente a Companhia de Jesus, foi fundada em 27 de setembro de 1540 pelo padre Inácio de Loyola e aprovada pelo Papa Paulo III sob a bula papal Regimini Militantis Ecclesiae (Para o Governo Militante da Igreja) (cf. WOODBRIDGE; JAMES III, 2013, v. 2, p. 205-07). O compromisso desta ordem era de reagir ao avanço protestante e, ao mesmo tempo, de ampliar o catolicismo romano além das fronteiras europeias (O’MALLEY, 2000, p. 127-28). Como esta ordem foi criada na contrarreforma, a fidelidade ao papado, bem como à própria Igreja

13 Os moinhos de vento verticais provavelmente se tornaram um símbolo nacional, porque além de serem inovações tecnológicas importantes, também foram utilizadas como plataformas militares para que as sentinelas estivessem sempre atentas no período da revolução liderada por Guilherme de Orange e de seus sucessores durante a Guerra dos Oitenta Anos. Para maiores informações sobre esse símbolo nacional holandês, ver BRENNER, Carla; RIDDELL, Jennifer; MOORE, Barbara. Painting in the Dutch Golden Age: a profile of the Seventeenth Century. Washington: National Gallery of Art Washington, 2007, p. 10.

14 Esses detalhes podem ser conferidos em BRITISH MUSEUM. DEPT. OF PRINTS AND DRAWINGS. Catalogue of Prints and Drawings in the British Museum. Division I: Political and Personal Satires. London: Order of the Trustees, 1870, p. 181. 
Católica eram lemas incontestes, de modo que Inácio de Loyola declarou: "Acredito que o branco que eu vejo é negro, se a hierarquia da igreja assim o tiver determinado" (LOYOLA, 1951, p. 160); contudo, outra coisa que chama bastante a atenção, é a roupagem que Armínio está vestido nesta gravura: são os trajes típicos de um cardeal católico, sugerindo que Armínio era um cripto-católico. ${ }^{15}$

\section{Considerações finais}

Seria Armínio um vilão ou um herói? Estaria ele pendendo mais para a verdade ou para a heresia? Seria um reformador ou um inimigo da Igreja? Embora a opinião possa variar nas análises enviesadas, essa parece ser uma discussão irrelevante, pois ele foi fiel à grande tradição da Igreja e não estava sozinho nas discordâncias com o calvinismo. Ademais, Armínio manteve a tônica que o reformacionismo holandês tinha originalmente, de irenismo, tolerância e de liberdade de consciência. Foi na mesma trajetória que seus seguidores, os remonstrantes, argumentaram em todo o processo sinodal. Desta forma, vê-lo como vilão ou herói, torna a discussão romantizada, pois o teólogo holandês foi acusado injustamente de pelagianismo e sofreu retaliações por ser mal compreendido. Ainda hoje, para algumas pessoas, Armínio é considerado um vilão, um dissidente da tradição soteriológica da Igreja. As acusações de pelagianismo ou semi-pelagianismo em sua teologia permanecem vivas. Em alguns casos por desconhecimento e, em outros, por mera desonestidade intelectual. Para outros entusiastas do arminianismo, Armínio tem sido considerado um herói e por ele, bem como por sua teologia, tais pessoas militam e acabam tomando caminhos monológicos e intolerantes muito parecidos com os calvinistas rígidos e que vão de encontro com toda a tradição arminiana.

O caminho ideal, obviamente, não é o de extremos. Armínio certamente teve sua importância na teologia cristã, mas elevá-lo ao pedestal de "herói" seria cometer algum tipo de idolatria. Ler sua história como um homem apenas injustiçado seria hagiologia e não queremos cometer tal erro aqui. Contudo, ao mesmo tempo, não entendo que o caminho seja de menosprezálo ou de reduzir sua relevância, como muitos calvinistas têm feito ao longo dos últimos 410 anos. Apesar de não ser simples dizer se Armínio poderia

\footnotetext{
Sobre as acusações de Armínio ter sido simpatizante com o catolicismo, bem como uma apresentação sensata de que nada disso passava de calúnias, ver COSSEE, Eric H. Arminius and Rome. In: STANGLIN, Keith; LEEUWEN, Th. Marius van. Arminius, Arminianism, and Europe: Jacobus Arminius (1559/60-1609). Boston; Leiden: Brill, 2009, p. 73-85.
} 
ser contado entre os reformadores ou não, entendo que esse seria um reconhecimento importante. Obviamente que isso vai depender de como se conceitua "reforma", bem como "reformador". Num sentido mais estrito, Armínio obviamente não poderia fazer parte, visto que o movimento já havia sido estabelecido na Holanda. Entretanto, ao incluir contemporâneos de Armínio (como Perkins, Beza e Junius) na lista, isso inequivocamente faria com que ele fosse digno de compor o seleto grupo. Outrossim, num sentido mais amplo, isto é, numa perspectiva de que a reforma é algo contínuo, como o calvinista holandês Gisbertus Voetius (1589-1676) insinuou quando reverberou o lema "Igreja Reformada Sempre Sendo Reformada" (REUVER, 2007, p. 16) durante o Sínodo de Dort, então é mais do que plausível admitir que foi isso que Armínio fez, pois ele propôs revisão da Confissão Belga, insistiu na realização de um Sínodo Nacional (que só aconteceu quase dez anos depois de sua morte) e avaliou os ensinos que não concordava à luz dos textos bíblicos, da tradição cristã e da razão.

\section{Referências bibliográficas}

ARMínIO, Jacó. As Obras de Armínio. Vol. 1. Rio de Janeiro: CPAD, 2015.

BANGS, Carl. Armínio: um estudo da Reforma Holandesa. São Paulo: Reflexão, 2015.

BANGS, Nathan. James Arminius: Formerly Professor of Divinity in the University of Leyden. New York: Harper and Brothers, 1843.

BRENNER, Carla; RIDDELL, Jennifer; MOORE, Barbara. Painting in the Dutch Golden Age: a profile of the Seventeenth Century. Washington: National Gallery of Art Washington, 2007.

BRIAN, Rustin E. Jacó Armínio: o homem de Oudewater. São Paulo: Reflexão, 2018.

British Museum. Dept. of Prints and Drawings. Catalogue of Prints and Drawings in the British Museum. Division I: Political and Personal Satires. London: Order of the Trustees, 1870.

CANNON, William Ragsdale. The Theology of John Wesley: with special reference to the doctrine of justification. New York; Nashville: Abingdon-Cokesbury Press, 1946.

COSSEE, Eric H. Arminius and Rome. In: STANGLIN, Keith; LEEUWEN, Th. Marius van (eds.). Arminius, Arminianism, and Europe: Jacobus Arminius (1559/60-1609). Boston; Leiden: Brill, 2009, p. 73-85.

COUTO, Vinicius. Anexo 02: As opiniões dos remonstrantes em 1618 com um memorial a Jacó Armínio. In: Em favor do arminianismo-wesleyano: um estudo bíblico, teológico e exegético de sua relevância na contemporaneidade. São Paulo: Reflexão, 2016, p. 373-388.

DANIELL, David. William Tyndale: a Biography. New Haven: Yale University Press, 2001.

DYRNESS, William; KÄRKKÄINEN, Veli-Matti (orgs.). Global Dictionary of Theology: a resource for the worldwide Church. Downers Grove: InterVarsity Press, 2008.

FARRIS, Michael. From Tyndale to Madison: how the death of an English martyr led to the American bill of rights. Nashville: B \& H Publishing Group, 2007. 
GEORGE, Timothy. Teologia dos Reformadores. São Paulo: Vida Nova, 1993.

GOTTFRIED, Johann Ludwig. Historische kronyck. Vervattende een nauwkeurige en volkomene beschrijvingh der aldergedenckwaerdigste geschiedenissen des weerelds, van den aenvangh der scheppingh tot op 't jaer Christi 1576. Leyden: Pieter vander Aa, 1698.

GUINNESS, H. Grattan. Interpretation and use of these prophecies in Reformation times. In: Romanism and the Reformation: from the Standpoint of Prophecy. Eugene: Wipf and Stock, 2007.

GUTHRIE, John. The life of James Arminius. Nashville: E. Stevenson \& F. A. Owen, 1857.

HARMS, Roeland; RAYMOND, Joad; SALMAN, Jeroen (Orgs.). Not Dead Things: the Dissemination of popular print in England and Wales, Italy, and the Low Countries, 1500-1820. Leiden; Boston: Brill, 2013.

JONES, Malcom. The English print. In: HATTAWAY, Michael (org.). A Companion to English Renaissance Literature and Culture. Malden: Blackwell Publishing, 2003.

LOYOLA, Ignatius. The spiritual exercises of St. Ignatius: a new translation based on studies in the language of the autograph. Chicago: Newman Press, 1951.

MIZAR. The Primitive Reformers (Ritratto di Martin Lutero con le principali figure della Riforma Protestante con in basso un cardinale, un diavolo, un papa e un monaco che tentano di spegnere la candela del protestantesimo). Roma: [s.d.], p. 1-2.

NIJENHUIS, Willem. Ecclesia Reformata: studies on the Reformation. Vol. 2. Boston; Leiden: Brill, 1994.

O'MALLEY, John W. Trent and all that: renaming Catholicism in the Early Modern Era. Cambridge: Harvard University Press, 2000.

PANOFSKY, Erwin. Significado nas artes visuais. São Paulo: Perspectivas, 1991.

REUVER, Arie de. Sweet communion: trajectories of spirituality from the Middle Ages Through the Further Reformation. Grand Rapids: Baker Academic, 2007.

SCHAFF, Phillip. The Creeds of Christendom. Vol. 3. Grand Rapids: Baker Book House, 1990. SPAANS, Joke. Face of the Reformation. Church History and Religious Culture. Utrecht, v. 97, n. 1, 2017, p. 408-451.

STEINMETZ, David C. Theodore Beza (1519-1605): eternal predestination and divine sovereignty. In: Reformers in the wings: from Geiler von Kaysersberg to Theodore Beza. New York: Oxford University Press, 2001, p. 114-122.

STOWER, C. The Monthly Repository of Theology and General Literature, vol. 7. Hackney: Longman, Hurst, Rees and Orme, 1813.

TYACKE, Nicholas. Anti-Calvinists: the rise of English Arminianism c. 1590-1640. New York: Oxford University Press, 1987.

TOLSMA, Marijke. Facing Arminius: Jacobus Arminius in Portrait. In: LEEUWEN, Marius van; STANGLIN, Keith; TOLSMA, Marijke. Arminius, arminianism and Europe: Jacobus Arminius (1559/60-1609). Boston; Leiden: Brill, 2009, p. 203-238.

TOLSMA, Marijke. Iconographia Arminiana: portraits from 1609 until ca. 1850. In:

LEEUWEN, Marius van; STANGLIN, Keith; TOLSMA, Marijke. Arminius, arminianism and Europe: Jacobus Arminius (1559/60-1609). Boston; Leiden: Brill, 2009, p. 239-261. 
WÖLFFLIN, Heinrich. Conceitos fundamentais da História da Arte: o problema da evolução dos estilos na arte mais recente. São Paulo: Martins Fontes, 2000.

WOODBRIDGE, John D.; JAMES III, Frank A. Church History: from Pre-Reformation to the Present Day - the rise and growth of the Church in Its Cultural, Intellectual and Political Context. Vol. 2. Grand Rapids: Zondervan, 2013.

Submetido em: 29-6-2020

Aceito em: 23-9-2020 